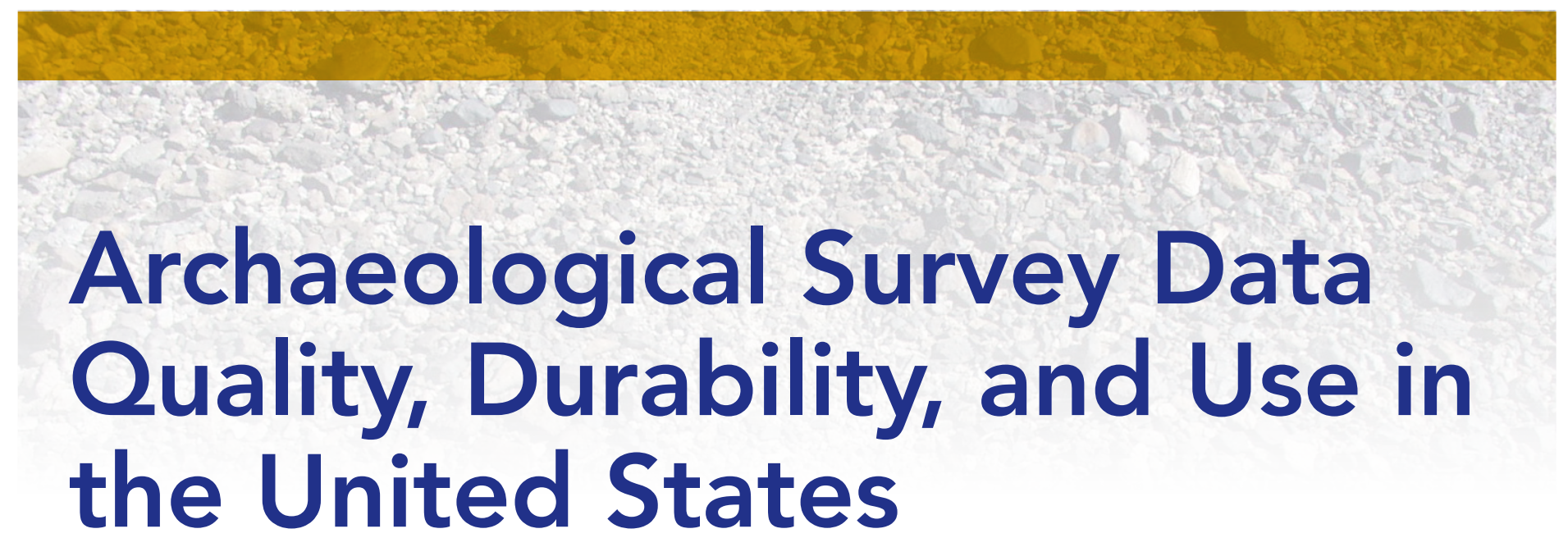

\title{
Findings and Recommendations
}

\author{
Richard H. Wilshusen, Michael Heilen, Wade Catts, \\ Karyn de Dufour, and Bradford Jones
}

Archaeological survey forms the backbone of

cultural resource management in the United States.

As such, archaeologists need to better understand the uses, durability, and quality of existing survey

data, as well as to improve future data collection.

Federal land managing agencies, State Historic

\section{ABSTRACT}

High-quality archaeological surveys and data are vital to preservation planning and mitigation efforts. Federal and state historic preservation offices (SHPOs) are accumulating and reviewing more data at an ever-faster pace. Given the critical nature of this information, a SAA task force was charged with assessing current survey practices and concerns. Our review indicates that survey policies and archaeological standards have improved substantially over the last two decades, but SHPOs remain challenged by insufficient professional training for field archaeologists, the need for standardization and integration of new technologies in field work, reporting, and review, as well as the sheer quantity and variety of digital data. A number of analytical tools and metrics are available to assess data quality, but seemingly there is not time or money for states to evaluate how to improve existing and future survey data. We draw upon a survey of SHPOs, a review of current literature, and our own experience to assess archaeological survey quality, data utility and durability for current and anticipated future uses. We offer suggestions on how to move forward, including consideration of an e-106 system for streamlining transfer and exchange of digital data and upgrading current approaches to survey and planning.

Prospección y datos arqueológicos de alta calidad son vitales para los esfuerzos de planificación y mitigación. Oficinas federales y estatales de preservación histórica (SHPOs) están acumulando y revisando datos a un ritmo cada vez más rápido. Dada la naturaleza crítica de esta información, una fuerza especial de SAA fue encargada de evaluar las prácticas de las prospecciones actuales y preocupaciones asociadas. Nuestra revisión indica que las políticas de prospecciones y los estándares arqueológicos han mejorado sustancialmente en las últimas dos décadas, pero SHPOs todavía enfrentan los desafíos de insuficiente entrenamiento profesional para los arqueólogos de campo, la falta de normalización y la integración de nuevas tecnologías en el trabajo de campo, presentación de informes y revisión de formas, así como por la gran cantidad de datos digitales. Una serie de herramientas y métricas de análisis están disponibles para evaluar la calidad de los datos, pero al parecer no hay tiempo ni dinero para que los estados evalúen cómo mejorar los datos de las encuestas actuales y futuras. Nos basamos en una encuesta de SHPOs, una revisión de la literatura actual, y nuestra propia experiencia para evaluar la calidad, la utilidad y la durabilidad de los datos arqueológicos para las necesidades actuales y futuras anticipadas. Ofrecemos sugerencias de cómo seguir adelante, incluyendo la consideración de un sistema de e -106 para agilizar la transferencia y el intercambio de datos digitales y la mejora de los enfoques actuales para prospección y planificación.

Advances in Archaeological Practice 4(2), 2016, pp. 106-117

Copyright 2016॰ㄱ The Society for American Archaeology

DOI: $10.7183 / 2326-3768.4 .2 .106$ 
Preservation Offices (SHPOs), Native American tribes and communities, and other stakeholders all rely on archaeological survey data to make decisions affecting cultural resources. Similarly, scholars utilize large, disparate survey datasets to perform micro- and macro-regional analyses to better understand the histories and effects of past human migrations, climate change, human adaptations, and cultural transformations. Indeed, many of the data developed largely through cultural resources management (CRM) work over the past several decades are of critical importance to addressing the grand challenges of archaeology (e.g., Kintigh et al. 2015). Yet most archaeologists agree that our 40 years of accumulated survey data are a mixed bag in terms of their quality and utility. Consequently, how do we move forward in a manner that integrates past data and current systems with dependable, realistic solutions that will advance our survey methods, data capabilities, and heritage planning and management needs?

We assume that current survey data are sufficiently reliable and accurate for the tasks we put them to, yet because archaeological methods and standards have generally increased in rigor and quality, we have to question the adequacy of "old" survey data. How can we help the agencies that fund or mandate inventories to decide when it is appropriate to resurvey areas? This question assumes singular importance as government budgets become tighter and as decisions about land use are under accelerating pressure from industry and the public. In addition, we must find methods and practices to ensure the shelf life of new survey data for anticipated future uses, whether it be focused primarily on research on the past, long-term management of present landscapes, or near-term future developments.

To examine these issues, the Society for American Archaeology (SAA) Board of Directors in October of 2014 approved the formation of an Archaeological Survey Data Task Force with a charge to address key questions such as:

- What are generally accepted standards of survey quality?

- What factors influence survey data quality, reliability, and longevity?

- What are best practices in terms of assessing survey quality, short of resurvey?

- When is resurvey necessary, and what degree of survey redundancy is useful?
By early December 2014, the charge for the task force had been finalized (Supplemental Appendix 1) and our five-person task force, along with our SAA Board Liaison (Jim Bruseth), was ready to get to work. Given our focus on site survey standards, practices, and data, our task force drew from the staff of various SHPOs and CRM professionals. Our members had over a century of combined experience working in the West, the Southwest, and the East. The small size of our task force facilitated rapid communication, meaningful debate, and quick decisionmaking. These characteristics were vital, given the two months we had to complete our task. We also recognized the limitations that this imposed on our research and our perspectives; our findings represent a snapshot of archaeological practice as seen through the lens of a survey of SHPOs. We strongly urge future investigators to draw in other interests, to hear additional concerns, and to seek additional expertise. Our findings and suggestions are intended to stimulate conversations, additional studies, and more substantial proposals for how we can improve our archaeological survey data to make them more useful and durable for the heritage management and research needs of government agencies, tribes, CRM professionals, and academic archaeologists.

This article focuses on understanding the assets and limits of our present survey data and highlights how to improve future survey data collection and use. Good survey data are fundamental to the ability to construct and use predictive models and develop regional planning programs, as described in Doelle et al. (2016) and McManamon et al. (2016).

We approached our task from three angles. First, we developed a questionnaire to obtain information from states and U.S. territories about their current archaeological survey standards and data requirements. The states and territories, with their survey databases managed by individual SHPOs or the agencies aligned with them, command the largest storehouse of survey data in the nation, and they set forth the requirements for survey within their individual jurisdictions. Second, we examined both the questionnaire results and the literature on survey practices and archaeological data quality to understand the inherent strengths and weaknesses of our current datasets and preservation-planning infrastructure. Third, based on what we gleaned from the questionnaire and literature review, we offer recommendations for how to accelerate our efforts to ensure greater consistency, longer shelf life, and better quality in our archaeological survey data.

One of the major changes taking place on many fronts is the shift from largely paper survey record systems to digital survey systems. As data are increasingly created, interpreted, exchanged, and curated within a digital environment, we also must consider the long-term needs of moving to a greater and more efficient digital exchange of survey, planning, and review data within the Section 106 consultation process. Whatever we do, we will affect the current direction of a $\$ 600$-million to onebillion-dollar-a-year CRM industry (Altschul and Patterson 2010; also ACRA 2016) and the practices of nearly 10,000 heritage management specialists (including archaeologists) working in the U.S. It will take time, persistence, and concerted effort from all three sectors of archaeology_-government, CRM, and the academy - if we are to transform our current archaeological inventory practices into a more powerful, widely used, and 


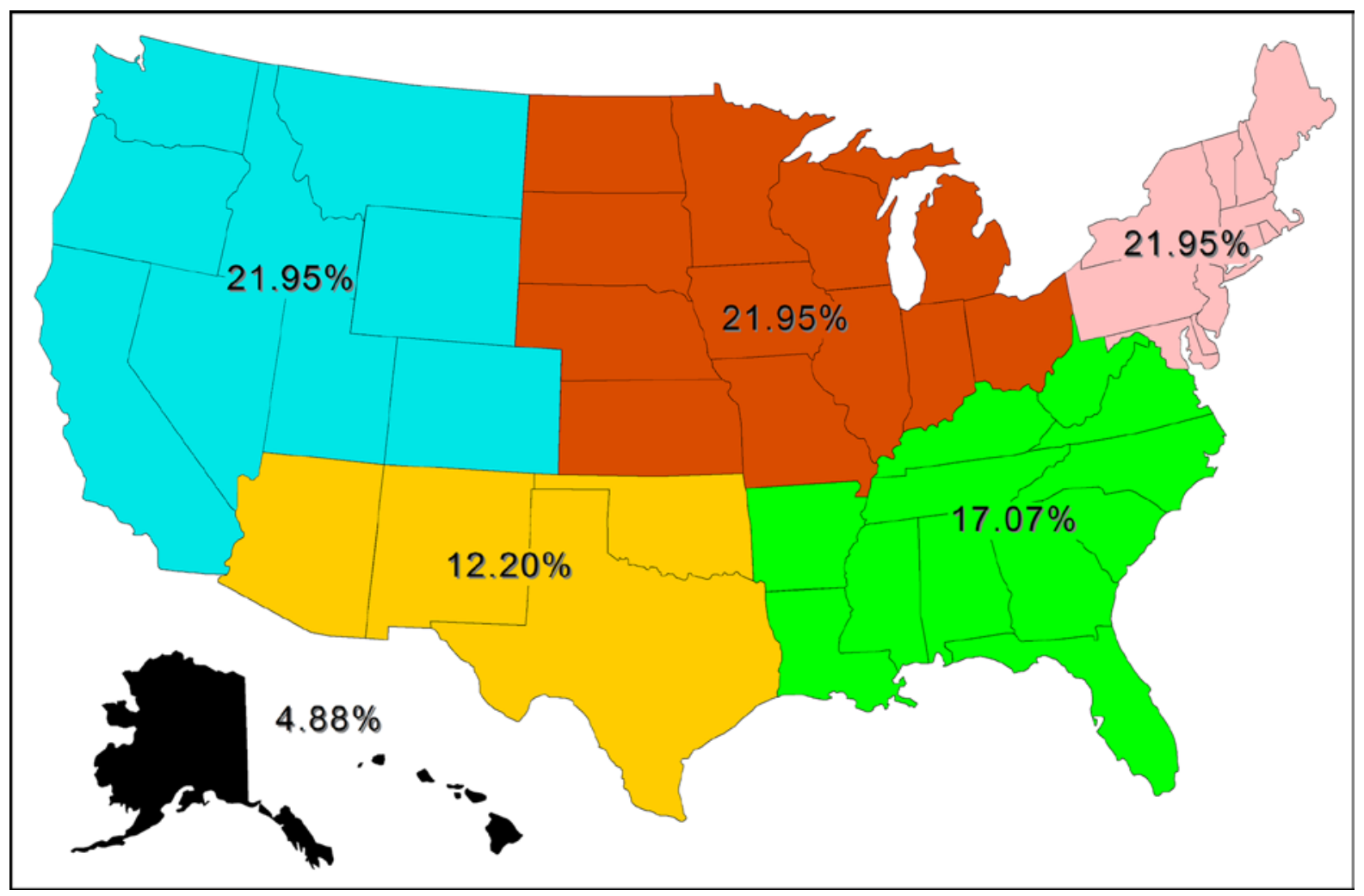

FIGURE 1. Map of the regional distribution of the 41 respondents to the survey. The percentages represent the regional contribution to the total. The one inconsistency in the numbers is that there were five respondents for the four states in the Southwest. Because the survey was kept anonymous, we could not detect which state supplied two responses. Otherwise, the data appear consistent with the responses we received.

interchangeable system for both management and research. Further, we must recognize that management and research are not separate from one another, but deeply interconnected, as most archaeological sites are judged eligible for inclusion in the National Register of Historic Places based on their research value. Research values are one aspect in management decisionmaking models that also incorporate a mix of heritage, ecological, and economic values.

\section{ARCHAEOLOGICAL SURVEY PRACTICE ACROSS THE UNITED STATES}

Our first task was to get a snapshot of current survey practice. To do this, we designed a short questionnaire (Supplemental Appendix 2) to examine the guidelines and practices employed by SHPOs and/or Offices of State Archaeologists. The questions were tested and refined to ensure clarity and to ensure that the questionnaire would take no more than 10 to 12 minutes to complete. We explained the reason for the survey in individual notes to the preservation offices in the 50 states and the District of Columbia (D.C.), as well as five territorial or commonwealth preservation offices. We asked them to volunteer their responses, with the assurance that we would conduct an anonymous survey, such that we would not track or be able to identify individual responses. A total of 41 offices responded (40 states and/or the district, plus one territory) from all across the U.S (Figure 1) between February 4 and 9, 2015. We asked the respondents to identify their regional affiliation only to ascertain the adequacy of our sample. Because we could not clearly identify regional ties beyond this one question, our analyses are limited to broad-brush conclusions, but we think this sacrifice was worth the forthright responses we received. We did not query Tribal Historic Preservation Offices or Certified Local Governments because of the short time we had to request information and thereafter to assemble our task force findings and recommendations. In our analysis, we note how many of the 41 answered each of our questions as some respondents did not answer all questions. We sometimes use "states" in place of "respondents," as the term carries more meaning and states represent more than 95 percent of the respondents. Graphic and tabular data summaries of the responses to each of the 12 questions are attached as Supplemental Appendix 3. These are the primary data we used to interpret the responses to our questionnaire.

Without a doubt, state offices of archaeology and historic preservation routinely handle an extraordinary quantity of survey data and make more daily decisions using these data 
than any other group of cultural resource managers we know of in the world. For example, in the 2013 fiscal year, SHPOs rendered decisions on National Register eligibility for 135,000 historic sites, objects, buildings, or districts (NPS 2014). At least half of these-and more likely two-thirds_-are archaeological resources; the remainder consist mostly of historic buildings and structures. This represents only a fraction of the total number of historic resources known to SHPOs, given that it represents only those resources that might have been affected by federal projects or discovered in Section 110 surveys in a single year.

The responses clearly demonstrate the importance of survey data to state offices. At least 90 percent of the states that responded provided state-specific guidance on survey protocols and requirements in addition to existing federal guidance, ranging from somewhat detailed survey guidance to the issuance of state-specific survey manuals. Only 10 percent noted that they deferred to federal standards instead of supplying state-specific guidance. Using the median values for the intervals we offered the SHPOs for their estimates, we project that in 2013 there was an absolute minimum of 24,000 surveys (41 responses) and at least 58,000 site forms (37 responses) reviewed by the SHPOs who responded. Using the average number of archaeological site reviews and surveys for the states that did respond, we estimate that at least 78,000 archaeological site forms were reviewed by all SHPOs nationwide in 2013 and approximately 29,000 field surveys were conducted. Although these are estimates generated from interval data, we think that they are good measures of SHPO workloads, given the more exact numbers for total site reviews $(135,000)$ —both archaeological and nonarchaeological-noted earlier from the 2013 Historic Preservation Fund Annual Report (NPS 2014). Based on personal experience, it is reasonable to estimate that 60 percent of all SHPO reviews, or approximately 80,000 site reviews, examine archaeological sites, as opposed to historic buildings or structures, even though there is likely considerable regional variation.

The survey and site data required by states are typically very detailed, with the majority of state offices collecting information, such as the location of the survey, number of acres surveyed, site number (Smithsonian or state equivalent), site type (e.g., lithic scatter, homestead, etc.), field recommendations of National Register eligibility, management suggestions, and so forth. In addition, 25 respondents also require the recording of clusters of smaller numbers of artifacts, often called "isolated finds," that do not meet a state's definition of an archaeological site. Many states have site forms with a minimum of four pages, and likely double or triple this number when attachments are included. These may include site overview photographs, descriptions and photographs of diagnostic artifacts, and computer-drafted maps showing the locations of tools, artifact concentrations, and features. In addition, site forms typically require inclusion of a U.S.G.S-based location map, shape files of the site boundaries and photo logs_-sometimes with GPS coordinates-for site overview, and other photographic documentation. Multiple hard copies on acid-free paper and usually digital versions for distribution to agencies must be reviewed and curated, either as site forms or as site summaries in project reports.

In the midst of this deluge of information, most SHPOs are also transitioning from paper documentation to digital records. At least 28 of the responding states regularly manage and share digital archaeological survey data, including geographic information system (GIS) layers and/or site data. Most of the others either have plans in the works or are moving to systems to allow the exchange, review, and management of digital information. Yet, given our ongoing dependence on paper records, only nine of the states that responded are actively limiting the amount of paper data submitted to their offices. It is clear that archaeologists, SHPOs, and the SAA must pursue digital solutions, as more and more archaeological data are "born digital."

The responses also revealed a noticeable percentage of resurvey of sites and areas that had already been recorded. A total of 35 respondents had some sense of the number of sites or amount of area being resurveyed: 11 states reported that 1-10 percent of the annual site surveys in their states involved some level of re-documentation, 17 that the resurvey rate is 11-20 percent, and 7 that resurvey of sites accounted for more than 20 percent of their site reviews (Figure 2). Given that many states began accumulating site data more than 40 years ago, the need for new site inventories and forms is obvious in some cases, a fact underscored by our results. Yet, in many cases, we are well past the point of needing resurvey in areas with high quality coverage; we must begin to evaluate the utility and nature of any resurvey.

When asked to rank the most common reasons for requiring resurveys, 30 respondents answered as follows: (1) too much time had passed since the previous inventory, (2) state survey standards had been made more rigorous since the time of the previous work, and (3) previous surveys were inadequate due to a lack of professional training or standards. Other responses included that poor ground visibility or disturbance at the time of the original reconnaissance necessitated a resurvey, time and budgetary limitations hindered earlier work, and the state office was now using a historic landscape approach in their planning efforts and previous surveys were inadequate for this level of planning. The most common time trigger for necessitating a new survey, based on 24 specific replies, was the lapse of 10-20 years (16 responses), with four offices asking for a resurvey if the previous work was older than 5 years, three stating that the earlier survey had to be 25 years or more in age, and one noting that they were reevaluating their standards.

SHPO responses demonstrate their concern for survey data quality. A surprising 51 percent of 35 respondents noted that their offices periodically spot-check the quality of surveys in their states. Quality control measures ranged from states using their own staff to hiring third parties to double check survey work. There was a wide range in the amount and kind of data required for site resurvey documentation, with the majority wanting at least a re-recording (or confirmation) of site location, extent, and condition and more than half of the offices asking for new photography and site maps. Over one-third required new in-field artifact and feature inventories, as well as new National Register eligibility recommendations.

When all the questions and comments are considered, it is evident that SHPOs have "upped their game" over the last two decades, requiring higher-quality survey methods, better reporting, and greater consistency in the overall professionalism of crews than was the norm 20-25 years ago. A variety of improvements have been seen over this time and we list a few here: 


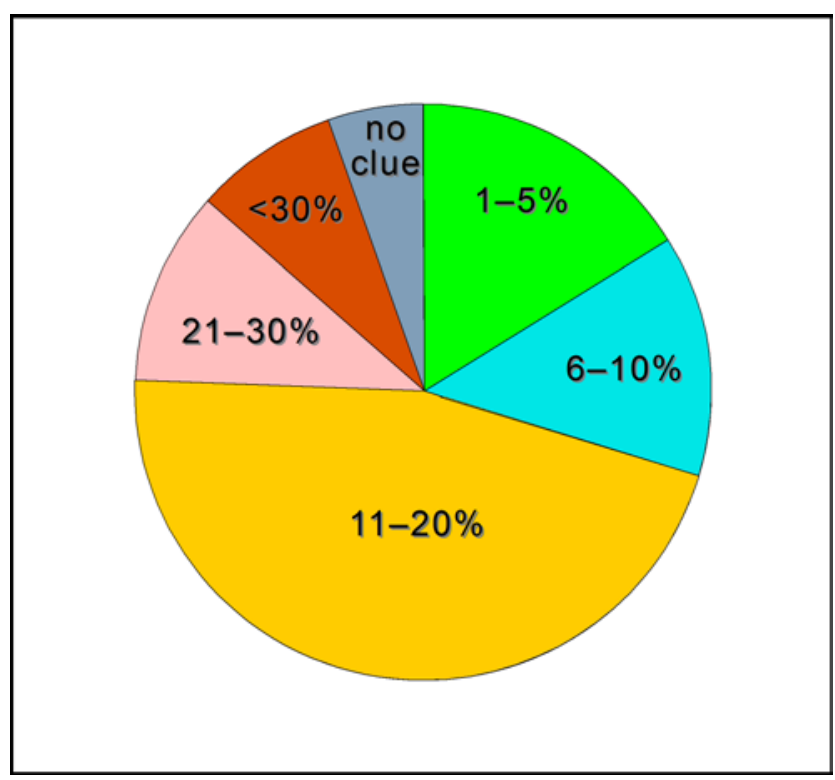

FIGURE 2. Estimated percentage of archaeological surveys that involve, at least in part, resurveys of previously recorded sites or surveyed areas (35 of 37 respondents were able to provide an estimate).

- $\quad$ Given the widespread adoption of GIS and more precise and reliable field instrumentation, including high-accuracy global positioning system (GPS) receivers, there is greater reliability in the mapping of sites and the establishment of their locations. Many challenges and errors remain, and instrumentation introduces new variables, but, overall, the quality of maps and site locations has noticeably improved.

- $\quad$ Survey and shovel-testing intervals appear to have become smaller and more standardized, and 26 of the 36 states addressing this question stated that pedestrian survey intervals of $19 \mathrm{~m}$ or less have become the norm. Our impression from informal conversations outside our present study is that shovel-testing intervals vary regionally, with tighter intervals $(7.5-15 \mathrm{~m})$ in the east and greater intervals in the west. Variability between states should not be surprising, given that shovel testing is most commonly applied for site discovery when terrain, surface visibility, or surface disturbances preclude effective identification of site features and materials through regular pedestrian survey. Again, our impression is that systematic shovel testing is more commonly employed as a survey method in the eastern U.S.; in the western U.S., shovel testing is more often used to supplement pedestrian survey methods.

We did not consider the challenges of coastal, marine, or wetland survey, as these issues were too complicated for our cursory review. More than a few SHPOs have specialists focused on just these settings and are considering steps to improve the quality, curation, and future usability of the data generated by marine and wetland surveys.

- The adoption of various methods employed for site detection has dramatically increased over the decades; more than 85 percent of the respondents noted that shovel testing is regularly used, 57 percent stated that geomorphological analysis was common, 51 percent mentioned the use of various geophysical detection methods, and 43 percent cited metal detection for site identification.

\section{IMPROVING SURVEY METHODS AND RESULTS AND TRANSFORMING OUR INFORMATION MANAGEMENT PRACTICES}

For decades, archaeologists have grappled with the question of which data to collect during survey and how to collect them (e.g., Heizer 1949:2-8; King 1978), but only in the last 20 years have we possessed sufficient survey data to truly assess the utility of particular variables and the replicability of our observations. In addition, over the last 30 years, state, federal, and academic archaeologists have been engaged in a losing battle with "Moore's law" (i.e., the observation that the number of transistors in an integrated circuit doubles approximately every two years [Moore 1965, 1975]). The pace at which we incorporate increasingly large numbers of small, affordable digital devices into CRM work will only increase. The amount of information we transmit, review, and store has accelerated geometrically as data generation has become easier, transmittal faster, and storage cheaper. Ideally, the data requirements for mandated archaeological survey should be tied to how those data will be used and how the data will be reviewed, exchanged, and curated, but as data have proliferated and data manipulation has become more complicated, this ideal sometimes evades our focus as we just try to keep apace. Will survey data be needed for developing historic contexts, archaeological modeling, and managing impacts? Will survey data be used to make a determination of eligibility, or will they be used simply to flag and avoid sites? How many data are needed, and how accurate and reliable should they be? What is their shelf life? Essentially, our review of survey issues diverged into the more archaeological issues of survey methodology and results, and then the attendant issue of dealing with past, current, and anticipated future data challenges.

\section{The Quality and Nature of Our Survey Data: What Do We Need All This Survey Data For and How Good Does It Need to Be?}

A number of responses to our questionnaire illustrated how SHPOs and planning organizations still struggle with the most basic issues in archaeological data quality. For example, resources documented by older surveys may not be located precisely where they have been recorded; site boundaries often change when sites are re-recorded; and the reliability of previous survey data is sometimes unclear or in doubt. A common, yet not always tested, assumption is that the most recently recorded data are accurate, while data recorded earlier in the history of survey are likely to be in error. The problem is not necessarily whether such data are accurate or inaccurate, but how accurate they are relative to how accurate they need to be. Moreover, what are the sources of variation in data quality and 
reliability? How do we deal with them to derive the information needed to interpret and manage archaeological resources?

Multiple studies have shown that survey methods have a strong effect on data quality (e.g., Banning 2002; Kintigh 1988; Shott 1985). Fundamentally, the probability of detecting an archaeological resource is determined by survey methods, ground conditions, surveyor training/bias, and the characteristics of the resource (e.g., Colwell and Ferguson 2014; Hilton 2003; Palumbo 2015). Although surveys are sometimes referred to as 100-percent or full-coverage survey, some resources fail to be detected through survey, regardless of the approach; there will be bias in what is detected and what is not. We need to consistently estimate survey error and evaluate the representativeness of our surveys, as well as the number and kinds of resources likely missed by a survey (Heilen et al. 2008). We do this type of assessment all too rarely, even as we increasingly need to find ways to measure the effectiveness of our surveys.

Site attribute data derived from survey are often needed for determinations of eligibility, developing management recommendations, and building regional syntheses and predictive models. It can, however, be difficult to integrate the results of multiple surveys, due to variation in data standards, analysis procedures, and recording techniques. For example, to limit curation costs, survey protocols in certain areas have begun to emphasize in-field artifact analysis in place of laboratory analysis, but little is understood about the accuracy of such assessments. A recent study demonstrated a low level of agreement among in-field and laboratory analysis in identifying commonly recorded artifact attributes (Heilen and Altschul 2013). Further, the more specific the artifact type or attribute, the less likely that an artifact will be correctly identified. The study concluded that the accuracy of many common field observations on artifact types and attributes is limited and that an acceptable level of accuracy is currently achievable only for some of the most basic artifact types and attributes.

New survey tools and methods certainly offer the potential to improve the comparability and reliability of our survey data. For example, recent mitigation research in New Mexico utilized handheld field recording devices to document sites within uniform grid cells in a manner that controlled many of the factors that inadvertently and adversely affect survey results, such as variation in survey intensity, boundary definition, artifact tabulation, or assessment of ground conditions. Although this system offered measurably significant improvements in data quality and comparability, managing the sheer volume of these data and integrating them into existing database structures posed major challenges. In addition, any advances such as this need to be comparable not only with methodologically similar surveys, but also with survey results derived from more traditional survey methods (Heilen and Murrell 2015).

The data from SHPOs demonstrated that resurvey comprises between 11 and 30 percent of all inventory work. This may be necessary for inventories done many years ago, but we need to examine the necessity of resurveys for meeting our larger heritage management goals. In a rare series of research-focused inventories and analyses in the Permian Basin in southern New Mexico, the Bureau of Land Management (BLM) found that resurveys often amounted to 15 percent or more of the total acreage inventoried for project planning, yet in a research survey of 6,385 acres, 100 percent of the large sites had already been recorded by prior surveys, even though only 28 percent of the area had been previously inventoried (Raymond et al. 2007; Schlanger et al. 2013). When smaller sites were taken into account, over 85 percent of all sites had been previously detected. Moreover, previous work by Sebastian and others (2005) in the Permian Basin showed that predictive models generated retrodictively using survey data accumulated at various points in time over the history of surveying an area stabilized after just 10 years. Collectively, these results suggested that enough had been learned about site location early in the history of survey, and additional gains were limited in subsequent decades of work in this area. This and other examples (Altschul et al. 2005) raise the question of whether we are spending our preservation dollars wisely (Larralde et al. 2016; Schlanger et al. 2013).

In the case of the Permian Basin, the BLM used this and other information to draft a new plan of action for dealing with archaeological survey and other matters pertaining to planning for energy developments on more almost 4,400 $\mathrm{km}^{2}\left(1,700 \mathrm{mi}^{2}\right)$ of BLM lands. Instead of investing in surveys that were yielding little in the way of preservation benefits and lots in terms of CRM and developer frustration, the new agreement plowed the funds that would have been used for survey back into alternative research and preservation in the area. Those efforts that traditionally would have been expended on yet more survey have instead been spent improving the BLM's ability to interpret and use existing data and to derive higher-quality data with improved or specialized methods. Other efforts have been focused on synthesizing survey and excavation results and refining research questions, methods, and historic contexts to improve understanding of the regional archaeological record (Larralde et al. 2016; Schlanger et al. 2013).

As we consider any refinements or improvements in current survey methodology or data, we also need to evaluate ways by which we can make our older survey data more usable and durable. Many times, almost half of the data in a SHPO or federal site survey database are more than 15 to 20 years old. We need to consider the potential strengths and weaknesses of these data and then evaluate how to scrub, filter, and normalize them (i.e., reduce undue redundancy) to enhance their strengths for particular purposes. Almost every SHPO has a meaningful percentage of sites recorded early in their history for which they have only dots on maps or site numbers, with little or no pertinent information. We need to evaluate whether these offer useful data or whether they are more likely noise at present.

Site components are often recorded using different terminology or definitional criteria. This makes it difficult to compare site records among multiple surveys to, for instance, look at all sites with a particular component type within a given area. Additionally, differences in field methods make it difficult to compare site density among surveys where sites have been recorded using differing survey intervals and site definition schemes. And, as regional CRM firms have become integrated into larger, corporate entities, a lack of regional archaeological understanding affects the quality of data. Despite these problems, the terminological and methodological dissonance within datasets, in many cases, can be made more harmonious. 
Finally, we need to consider the appropriate scale at which we can utilize our data for any given purpose and understand the uses to which we may or may not reliably put them. Many archaeological management plans are focused on individual site avoidance and "just-in-time" preservation issues, rather than long-term, landscape-level management planning. Yet energy development (Colwell and Ferguson 2014; Heilen and Murrell 2015; Schlanger et al. 2013; Sesler et al. 2000), ecological planning (Anschuetz 2005; Bocinsky and Kohler 2014; Lightfoot et al. 2013; Ryan et al. 2012), climate change threats (Holtz et al. 2014; Wells et al. 2014), and many current academic research questions are best addressed at the landscape level. Climate change, ongoing suburban and industrial development, and the increasing loss of sites to massive fires, coastal erosion, sea level rise, and floods increasingly create preservation conundrums that cannot be addressed with our existing plans and organizational capabilities. We must begin to adapt our current survey practices and systems to allow for more rapid collection, assembly, transmittal, and review of these data. We need to make better use of our existing inventory data to plan for landscape-level contingency plans to address current and future threats to our heritage.

\section{The Need to Transform Our Data Management Practices}

Few who have worked outside of a SHPO or a federal office will fully understand the wide range of responsibilities of these offices. One of the primary duties of a SHPO is to consult with federal agencies under Section 106 of the National Historic Preservation Act, which requires federal agencies to consider the effects of projects they carry out, approve, or fund on historic properties. Many SHPOs handle thousands of separate consultations a year with only a handful of staff, yet Section 106 consultation represents only one aspect of a SHPO's responsibilities. More importantly for this study, SHPOs also normally maintain the state's inventory of historic properties that are identified as a part of the Section 106 review process. Federal and tribal archaeological oversight and information gathering responsibilities are also complex, yet in the majority of cases these state, federal, and tribal offices are underfunded, understaffed, and have infrastructures and practices that limit many business processes to the transmission of paper reports, business letters, and the manual input of digital data from these paper reports.

Many of these inventory systems are outdated and have not kept up with more recent advances in database technology, making it difficult to conduct effective searches and retrieve relevant records for large study areas. Synthesis of data and critical examination of their distribution are beyond the budgets of almost all states, yet evaluation of how useful these data are for landscape-level research and management is necessary for preservation planning. SHPOs routinely make their data accessible to appropriate users and these data-sharing programs are critical in planning for surveys, writing reports, and consultations, but the limitations of these systems were a clear concern for SHPOs based on our survey. CRM professionals voiced similar concerns in a recent discussion of the topic at the American Cultural Resources Association (ACRA) annual meeting (Wilshusen 2015).
The present pressures on SHPO and federal information management systems will only become more intense in the coming years, as CRM firms and researchers turn increasingly to paperless systems in field data collection (Sharp and Litschi 2014). Although we are not in a position to offer a singular solution, we suggest alternatives that are worth exploring. We recommend improvements to three integral elements of our current survey and data management practices: (1) the Section 106 review process, (2) the survey observations and data themselves, and (3) access to and curation of these data. We also challenge the profession to address the concerns we have raised and to respond to the recommendations we have offered.

\section{CONCLUSIONS AND RECOMMENDATIONS}

We believe that we are at a "Detroit moment" in archaeology. We have built a big, powerful preservation machine, but like the U.S. auto industry in the late 1960s, it is a machine that is not very flexible or adaptable for present and future needs. A tremendous amount has been accomplished and vast stores of data and material (from site forms to curated artifact collections) have been accumulated. Now, professional archaeologists need to think hard about how to reinvent our practices and our policies to address the challenges summarized above. We need to adapt our current survey systems to make them more efficient, effective, and nimble for managing our heritage resources. At the same time, we must find ways to provide the research and education opportunities that affirm their public value. This last point is crucial: we must demonstrate the worth of what we do.

The responses to our February 2015 questionnaire regarding current archaeological survey methods and data demonstrate that contemporary survey policies and practices have notably improved and become more standardized over the last decades. It is also clear that both SHPOs and archaeological researchers recognize the need for ongoing improvements in methods for making survey data more useful and durable. As discussed above, we need to reexamine our use of resurvey in areas that have already received significant survey coverage, and certainly we must reexamine and utilize older collections in new analyses. Perhaps it is more important to evaluate the utility of the data we have collected and to consider the data now needed to answer research questions and improve preservation outcomes. The need for continued improvements takes on additional urgency as more of our survey and excavation data are born digital and there are moves towards a fully digital Section 106 review process increasingly focused on landscape-level heritage management questions.

\section{The Section 106 Review Process: Let's Explore Digital Alternatives!}

If we are to move to a digital future, it is critical that we prepare for a transition to what might be called an e-106 process. A more fully digital exchange of documents and data as part of the Section 106 consultation process should focus on processes that significantly speed up consultations, accelerate straightforward decisions regarding development options, decrease long-term personnel and physical storage costs, provide faster 
integration and dissemination of data to partners and mechanisms for quality control, eliminate redundancy, and ensure sustainability and security. Without such improvements, we predict an increasing erosion of a SHPO's abilities to meet consultation timeframes for Section 106 reviews and emergency situations, such as forest fires, flooding, and storms. Perceived bureaucratic delays to projects and emergency relief can have severe political and financial consequences for state archaeologists, compliance offices, and the CRM industry.

Such a transformative movement in digital systems and processes must necessarily engage federal, state, tribal, and other partners at key points in the design, development, and test stages of the effort. New Mexico, Washington, and Virginia have significantly upgraded their SHPO data systems, and we can learn from their experiences. Other states may undertake more modest, but important, improvements that allow site data to be made available on a secure web-based system. If SHPO databases are not already spatially enabled, we predict that they will be soon.

A recent study performed as part of the National Cooperative Highway Research Program (NCHRP) for the American Association of State Highway and Transportation Officials interviewed states to identify the ways that they used or planned to use cultural resources GIS, and to assess the costs and benefits to states of having and using a cultural resources GIS. The study also determined that each state intends to develop or is in the process of developing or refining a statewide cultural resource GIS. Each state has, or is working to have, the following datasets integrated into their statewide system (Ingbar et al. 2015):

\section{- $\quad$ Site locations and boundaries}

- $\quad$ Survey area locations and boundaries

- Legal status of identified resources, including NRHP eligibility

- $\quad$ Digitized records of site and project forms, inventory reports, Section 106 compliance documentation, and other cultural resources data

Clearly, there will be variability among states and regions in the specifics of how resources are defined and attributed, as well as how data will be distributed and used within a statewide system. Moreover, some states are legally bound by state law to maintain paper records or meet legal criteria that would affect their transition to a digital system.

Data sharing, security, and access are critical aspects of any e-106 system. Such a system must allow access to the database by appropriate consulting agencies and partners. Some SHPOs have significant portions of their data saved as scanned documents and differences in data capture and storage practices will create a certain variance in the solutions sought by different states. Given the nature of SHPOs, we anticipate that new systems will need robust data summary report-writing capabilities and the ability to generate automated correspondence. With the shifts that we are seeing in current computing, it seems that the integration of data collected by disparate apps will be a key element of any new system.
There is more to designing and implementing an e-106 solution than what we offer above. Our point is that Section 106 is a key element that unites preservation practices in the U.S., and its successful fulfillment is based on the efficient exchange and accessibility of critical survey data. As such, modernizing Section 106 information technology and improving our survey practices and data may be more intertwined than some might suspect.

\section{Improving the Quality, Utility, and Durability of Our Survey Data: The Need for Consensus on Minimal, Yet Critical, Standards}

Our research identified a variety of metrics and analytical tools that are available to assess data quality, including estimates of discovery probabilities, numbers and kinds of sites likely to be missed by survey, and the accuracy of in-field artifact identification. Additional methods are also needed to help us flag questionable data, standardize information from multiple projects, and evaluate the effects of variation in data quality on our interpretations and management recommendations.

To ensure that data remain durable and their quality can be assessed, appropriate metadata are needed. These might include technical information such as survey intervals, shoveltest design and actual tests dug, ground conditions, and site-definition protocols. Information on mapping instruments, global positioning system (GPS) units, and GIS technology used in creating survey data would also be useful. To prevent loss or degradation of data, it is important to choose appropriate storage formats and mediums. To achieve these goals, we must begin to develop data management plans specifying data requirements and standards, quality control measures, digitization of old records, curation and access protocols, and data integration and updating strategies. This is going to test our current systems, and all of us-SHPOs, federal archaeologists, CRM professionals, and academic archaeologists - must begin to think creatively about how we can address this need.

Improving our field and lab analyses will take a combination of both new methods and technologies and increasing attention to addressing how our data will be used and how to ensure their quality. We must continue to refine our methods for estimating and controlling error in archaeological observations and for standardizing information from multiple surveys to improve data reliability and utility for both planning (Laurenzi et al. 2013) and research (Mills et al. 2015; Ortman et al. 2007). Much of this improvement is likely to go hand in hand with the application of digital tablets and other GPS- and GIS-enabled personal digital devices to fieldwork. The development of digital data entry systems for both spatial and aspatial data will require careful consideration of how the data are generated; how they will be stored, related, and updated within an integrated digital system; and how they will be used to fulfill Section 106 management needs, including research and regional synthesis.

In addition, SHPOs and federal agencies must find dependable ways to better monitor, control, and enforce the quality of work done by permitted field archaeologists, as well as to increasingly standardize and ensure the quality and durability of the survey data we collect, manage, and use. SHPOs and federal agencies 
should be strongly encouraged to develop remotely accessible and up-to-date digital interfaces for sharing archaeological survey data and reports and ways to access and manipulate parent data by qualified personnel for synthesis and analysis. The increasingly national and international scale of many CRM firms makes the availability and quality of regional survey resources all the more critical. This is a national need that must also address state issues.

What is needed is for historic preservation offices, land managers, and practicing archaeological professionals to come together to decide the most effective way to assess current survey standards and guidelines. Based on the results of the assessment, a small task force could then be empowered to recommend updated minimal standards for digital survey data that will ensure durable, high-quality, interoperable survey data for the future. Guidelines will need to be sensitive to regional differences in survey practices reflecting a range of influences, such as the percentage of federal land in a state, the nature of the archaeological record, and the extent of urban, industrial, and agricultural development.

\section{Addressing Our Big Data Problem: Thinking Both Inside and Outside Our State Boundaries}

We now have at our disposal in many states an enormous quantity of data, warts and all. A wide range of biases and quality control problems certainly affect these data, but until we begin to synthesize and use these data at a broad scale, including across jurisdictions and platforms, we will not fully recognize their utility, nor their problems and prospects for improvement. As a discipline, we need to decide how we can use and improve our existing data, which data are most critical for the future, and how we are best able to access and manipulate data to answer major research questions and address both short- and long-term preservation needs. We need to improve the utility of these data and our research by finding ways to make them more accessible to researchers and the public-whose support is critical to the continuance of this work-without compromising site security.

There is currently a wide degree of variability in the GIS and database systems employed by individual states. Some states have built large and complex database systems and have a substantial proportion of their survey data digitized. Other states have more basic databases and may still maintain a largely paper record system (Ingbar et al. 2015). For some states, digitization means the scanning of site forms to produce digital copies, while for others this means developing complex relational databases with many standardized attributes recorded in numerous related database tables and fields. All these factors affect the degree to which records can be searched, retrieved, and manipulated. For example, if digital site records are searchable but do not require discrete standardized input for particular variables, such as from a drop-down list, finding all records that list a particular kind of feature, diagnostic artifact, or temporal affiliation can be highly unreliable due to variation in spelling, terminology, typology, and where within a site record a given piece of information can be and is recorded.
Ultimately, the variation among states in methods, practices, site records, and database formats means that it will be difficult to create a uniform national system that encompasses all the variation. More than likely, individual states will need to develop and refine their own systems. Some states are further along in developing digital data systems, but all would likely benefit from federal funds earmarked for the development and refinement of databases and GIS, and all can benefit from a common set of basic standards similar to the geospatial data standards put forth by the Federal Geographic Data Committee (see, e.g., McCarthy 2009). There are several ways in which individual state databases could be integrated and related; one existing model is the ontological matching scheme being developed by Digital Index of North American Archaeology (DINAA). Other means of interstate data coordination might include mitigation-specific cross-state planning efforts needed for large energy transmission lines (e.g., LEAP 2016).

As states move toward management systems that allow the development, exchange, and curation of data to be fully digital, there are a number of issues that should be carefully considered. First, such systems need sophisticated backup plans and protocols, such as can be provided by the Digital Archaeological Record (tDAR) or similar heritage data curation systems, to ensure that data are not lost in the case of disasters or obsolescence of software programs. Second, the way data are digitized should dovetail with processes for populating CRM database fields and generating automatic reports and quality-control checks. For example, when data are entered into a particular digital form, such as a site record, it is possible for those same data to be simultaneously entered into a reviewable database so that the data do not have to be entered twice, saving time and money that can be put to other uses and minimizing the potential for data-entry error. Further, excepting descriptive text, many data could be entered in forms and related databases as standardized terms, values, counts, and measurements, allowing the data to have comparability among projects and greater utility for analyzing results of multiple projects in flexible and creative ways. If the canons used for these data are consistent across a state or an agency, then federal and state reviews of these data and their acceptance or correction should be significantly accelerated. This should also facilitate the merging and curation of the data in federal, SHPO, or other secure heritage data systems. Third, the challenges of linking site records to GIS need to be addressed. In many SHPOs, cultural resource databases and associated GIS are often built using separate systems and programs requiring additional steps to link the GIS data and the resource data. Versioning issues often create incompatibilities among programs that necessitate frequent updates, making it difficult to maintain a functioning system that relies on interoperability of multiple software programs and database systems.

\section{Our Charge to the Profession}

We began our research tasked to address questions such as whether there were common standards for data quality, reliability, and longevity across the U.S. and to assess the best practices for survey so that we might limit the need for a significant amount of resurvey. A questionnaire-based survey of historic preservation offices offered a richly textured snapshot of state and U.S. territory survey standards, practices, and concerns. In light of these results and after reviewing the recent research 
literature on survey practices and innovations, we are struck by the immense amount of archaeological site data collected each year and the surprisingly high quality and greater than expected conformity of current survey data and practices. We also were impressed by the immense challenges posed by the need to integrate modern data collection and curation practices with existing older, poorly funded systems, as well as the necessity of making digital sense of the tremendous variability in the legacy survey data of the last four decades of mitigation work. Given that there has been a primary focus on protecting heritage at a site-by-site level of engagement, a great deal of research still needs to be done to understand larger cultural or heritage landscapes. We will need to normalize and synthesize existing state survey data if we are to use these data to achieve our long-term heritage management goals.

Following our charge from the SAA for this task force, we now offer a charge to the profession, along with questions that need to be addressed nationally:

- Federal agencies, states, and tribes need to agree on the most essential, effective, and reliable archaeological and ethnographic data that are critical for short-term preservation management issues, long-range heritage planning and management, and that can be readily accessible for emergency situations. In short, what are the most fundamental data needed for heritage management decision-making? The profession has oftentimes sidestepped this most elementary of questions in its headlong pursuit to collect more and more data. This question can be answered.

- It is clear that state and federal archaeologists, in collaboration with tribes, CRM firms, and nonprofit research groups, need to create consortia to cooperate and also to obtain private/public funding to create applications and techniques that begin to address some of our shared digital challenges. These include the need for greater integration of old and new survey data, the exchange of interstate and interagency data for the gradual move to a digital consultation process, and the incorporation of some of the innovations allowed by current digital survey data collection practices. Our question to SAA is: How do we begin to accomplish this so that at least several regional experiments are underway by two years from now? We recognize that many other groups-tribes, states, federal agencies, CRM firms, universities, and others-have a vital stake in this issue, but, fundamentally, it is a question for the entire profession.

- For university researchers, CRM archaeologists, and tribal archaeologists our question is: What are the fundamental research issues, the so-called grand challenges, which can be addressed at a large-scale level using archaeological and cultural data (e.g. Kintigh et al. 2014)? What are those data and findings that can serve to educate our many publics about the past and the importance of our heritage for our future? What are the most important survey improvements that are needed to address these issues?
- $\quad F i n a l l y$, what are the means or where is the forum whereby we can begin to regularly validate, review, and agree upon existing best practices, new standards or guidelines, and potential innovations in our cultural resource surveys? We need to set goals for ourselves if we are to measure our progress over the next five years. We invite our professional groups to produce individual five-year plans-by a year after the publication of this article-that propose how they will contribute to addressing these issues through specific actions and anticipated achievements.

\section{Acknowledgments}

The 41 respondents to our questionnaire provided essential information that shaped these findings. We are grateful to the many SHPO staff and state archaeologists who readily responded to our inquiry. We can only thank them here because their participation was anonymous, with the exception of some who have identified themselves to us at the end of the survey or in conversations thereafter. Key staff at Colorado's Office of Archaeology and Historic Preservation made crucial improvements to the wording and format of the questionnaire and later provided critical skills needed in the tabulation and presentation of the results. We thank Stephanie Boktor, Holly Norton, Mary Sullivan, and Mark Tobias for service above the call of duty. Our SAA Board Liaison, Jim Bruseth, offered crucial counsel and came to our rescue at least twice. Phil Geib drafted our two figures and Maria Sarur Zanatta significantly improved the original Spanish translation of the abstract by Richard Wilshusen. We also appreciate the patience and advice of the editors as we revised the manuscript. Finally, the original task force findings and recommendations have been considerably expanded for publication, and the senior author takes responsibility for errors, misinterpretations, or over ambitious goals that may have crept into this more wide-ranging consideration of the issues.

\section{Data Availability Statement}

Cumulative data from each question on the state questionnaire (Supplemental Appendix 2) are presented in tabular and graph form in Supplemental Appendix 3. Identifying statements in the comments have been redacted to ensure the anonymity of the respondents, but otherwise represent the raw data used in our analyses.

\section{Supplemental Materials}

Supplemental materials are accessible via the SAA member login at www.saa.org/members-login:

Supplemental Appendix A: Archaeological Survey Data Quality, Durability, and Use Task Force.

Supplemental Appendix B: Text Used in the Online Questionnaire for the Survey of State Archaeological Programs.

Supplemental Appendix C: Survey of State Archaeological Programs. 


\section{REFERENCES CITED}

Altschul, Jeffrey H., Terry H. Klein, and Lynne Sebastian

2005 A Workshop on Predictive Modeling and Cultural Resource Management of Military Installations, Santa Fe, New Mexico, November 15-18, 2004. Legacy Resource Management Program, Legacy Project 03-167. Electronic document, http://www.denix.osd.mil/cr/upload/ WORKSHOP-ON-PREDICTIVE-MODELING-2005.PDF , accessed February 9, 2016.

Altschul, Jeffrey H., and Thomas C. Patterson

2010 Trends in Employment and Training in American Archaeology. In Voices in American Archaeology, edited by Wendy Ashmore, Dorothy T. Lippert, and Barbara J. Mills, pp. 291-316. Society for American Archaeology, Washington, D.C.

American Cultural Resources Association (ACRA)

2016 Making the Economic Case for CRM. http://www.acra-crm. org/?Advocacy, accessed February 6, 2016.

Anschuetz, Kurt

2005 Landscapes as Memory: Archaeological History to Learn From and to Live By. In Engaged Anthropology: Research Essays on North American Archaeology, Ethnobotany, and Museology, Papers in Honor of Richard I. Ford, edited by Michelle Hegmon and B. Sunday Eiselt, pp. 52-72. Anthropological Papers No. 94. Museum of Anthropology, University of Michigan, Ann Arbor

Banning, E. B.

2002 Archaeological Survey. Kluwer Academic/Plenum Press, New York.

Bocinsky, R. Kyle, and Timothy A. Kohler

2014 A 2000-Year Reconstruction of the Rain-Fed Maize Agricultural Niche in the US Southwest. Nature Communications 5:5618.

Colwell, Chip, and T.J. Ferguson

2014 The Snow-Capped Mountain and the Uranium Mine: Zuni Heritage and the Landscape Scale in Cultural Resource Management. Advances in Archaeological Practice 2(4):234-251.

Doelle, William H., Pat Barker, David Cushman, Michael Heilen, Cynthia Herhahn, and Christina Rieth

2016 Incorporating Archaeological Resources in Landscape-Level Planning and Management. Advances in Archaeological Practice 4(2):118-131.

Heilen, Michael, and Jeffrey H. Altschul

2013 The Accuracy and Adequacy of In-Field Artifact Analysis: An Experimental Test at Two Archaeological Sites in the Western United States. Advances in Archaeological Practice 1(2):121-138.

Heilen, Michael, and Monica Murrell (editors)

2015 An Assessment of Transect Recording Unit Survey and Subsurface Testing Methods at Four Sites in the Permian Basin, New Mexico. Technical Report 15-68, Statistical Research, Albuquerque.

Heilen, Michael, Christopher Nagle, and Jeffrey H. Altschul

2008 An Assessment of Archaeological Data Quality: A Report Submitted in Partial Fulfillment of Legacy Resource Management Program Project "To Develop Analytical Tools for Characterizing, Visualizing, and Evaluating Archaeological Data Quality Systematically for Communities of Practice within the Department of Defense." ERDC-CERL. Technical Report 08-65. Statistical Research Inc., Tucson. Electronic document, http://www. denix. osd. mil/cr/upload/07-353-Assessment-of-Archeological-Data-QualityFINAL.pdf, accessed February 10, 2016

Heizer, Robert F.

1949 A Manual of Archaeological Field Methods. The National Press, Millbrae, California.

Hilton, Michael B.

2003 Quantifying Postdepositional Redistribution of the Archaeological Record Produced by Freeze-Thaw and Other Mechanisms: An Experimental Approach. Journal of Archaeological Method and Theory 10:165-202.

Holtz, Debra, Adam Markham, Kate Cell, and Brenda Ekwurzel

2014 National Landmarks at Risk How Rising Seas, Floods, and Wildfires Are Threatening the United States' Most Cherished Historic Sites.
Electronic document, www.ucsusa.org/LandmarksAtRisk, accessed October 20, 2015.

Ingbar, Eric, Terry H. Klein, and Melissa Cascella

2015 Application of Geographic Information System for Historic Properties. National Cooperative Highway Research Program 25-25, Task 90. Report prepared for American Association of State Highway and Transportation Officials, Washington, D.C.

King, Thomas F.

1978 The Archaeological Survey: Methods and Uses. Electronic document, http://www.fire.ca.gov/resource mgt/archaeology/downloads/ archsurveymethods.pdf, accessed October 19, 2015.

Kintigh, Keith

1988 The Effectiveness of Subsurface Testing: A Simulation Approach. American Antiquity 53:686-707.

Kintigh, Keith W., Jeffrey H. Altschul, Mary C. Beaudry, Robert D. Drennan, Ann P. Kinzig, Timothy A. Kohler, W. Fredrick Limp, Herbert D. G. Maschner, William K. Michener, Timothy R. Pauketat, Peter Peregrine, Jeremy A. Sabloff, Tony J. Wilkinson, Henry T. Wright, and Melinda A. Zeder 2014 Grand Challenges for Archaeology. American Antiquity 79:5-24.

Kintigh, Keith W., Jeffrey H. Altschul, Ann P. Kinzig, W. Fredrick Limp, William K. Michener, Jeremy A. Sabloff, Edward J. Hackett, Timothy A. Kohler, Bertram Ludäscher, and Clifford A. Lynch

2015 Cultural Dynamics, Deep Time, and Data Planning Cyberinfrastructure Investments for Archaeology. Advances in Archaeological Practice 3(1):1-15.

Larralde, Signa, Martin Stein, and Sarah H. Schlanger 2016 The Permian Basin Programmatic Agreement after Seven Years of Implementation. Advances in Archaeological Practice 4(2):149-160 .

Laurenzi, Andy, Matthew A. Peeples, William H. Doelle

2013 Cultural Resources Priority Area Planning in Sub-Mogollon Arizona and New Mexico. Advances in Archaeological Practice 1(2):61-76.

Leaders in Energy and Preservation (LEAP)

2016 Screening Tool: About. Electronic document, http://www. energyandpreservation.org/about-screening-tool/, accessed February 6 , 2016.

Lightfoot, Kent G., Rob Q. Cuthrell, Chuck J. Striplen, and Mark G. Hylkema 2013 Rethinking the Study of Landscape Management Practices Among Hunter-Gatherers in North America. American Antiquity 78(2):285-301.

McCarthy, Deidre

2009 Historic Preservation Response Methodology: Based on the Katrina Response Model. Heritage Documentation Programs, National Park Service, Washington, D.C.

McManamon, Francis P., John Doershuk, William D. Lipe, Tom McCulloch, Christopher Polglase, Sarah Schlanger, Lynne Sebastian, and Lynne Sullivan

2016 Task Force Report on Valuing Archaeological Resources. Advances in Archaeological Practice 4(2):132-148.

Mills, Barbara J., Matthew A. Peeples, W. Randall Haas, Jr., Lewis Borck, Jeffery J. Clark, and J.M. Roberts, Jr.

2015 Multiscalar Perspectives on Social Networks in the Late Prehistoric Southwest. American Antiquity 80:3-24.

Moore, Gordon E.

1965 Cramming More Components onto Integrated Circuits. Electronics Magazine 38(8): 82-85.

1975 Progress in Digital Integrated Electronics. Speech text from International Electron Devices Meeting, Institute of Electrical and Electronics Engineers (IEEE), 1975, pp. 11-13. Electronic document, http:// www.eng.auburn.edu/ agrawvd/COURSE/E7770 Spr07/READ/Gordon Moore 1975 Speech.pdf, accessed October 19, 2015

National Park Service (State, Tribal, and Local Plans and Grants Division) 2014 The Historic Preservation Fund Annual Report. Electronic document, http://ncshpo.org/2013 Historic Annual Report web.pdf, accessed September 1, 2015

Ortman, Scott G., Mark D. Varien, and Lee Gripp 
2007 Empirical Bayesian Methods for Archaeological Survey Data: An Application from the Mesa Verde Region. American Antiquity 72:241-272.

Palumbo, Scott

2015 Assessing the Utility of Plowed Field Surface Deposits in Pilot Research. Advances in Archaeological Practice 3(1):78-92.

Raymond, Gerry, Nina Harris, Jalesa Johnson, and Stephen Yost

2007 Class III Survey and Selective Spatial Data Analyses of 6,385 Acres on the Western Block I Lease in Pierce Canyon, Eddy County, New Mexico. Prepared by Ecosystem Management, Inc., for the New Mexico Bureau of Land Management, Consultant Report Number 50708.

Ryan, Kevin C., Ann Trinkle Jones, Cassandra L. Koerner, and Kristine M. Lee (editors)

2012 Wildland Fire in Ecosystems: Effects of Fire on Cultural Resources and Archaeology. General Technical Report no. 42, vol. 3. U.S. Department of Agriculture, Forest Service, Rocky Mountain Research Station, Ft. Collins, Colorado.

Schlanger, Sarah, George MacDonell, Signa Larralde, and Martin Stein

2013 Going Big: The Permian Basin Memorandum of Agreement as a Fundamental Shift in Section 106 Compliance. Advances in Archaeological Practice 1(1):13-23.

Sebastian, Lynne, Jeffrey H. Altschul, Chris M. Rohe, Scott Thompson, and William E. Hayden

2005 Adaptive Management and Planning Models for Cultural Resources in Oil and Gas Fields in New Mexico and Wyoming: Final Technical Report. U.S. Department of Energy Technical Report. Gnomon, Inc., Carson City, Nevada.

Sesler, Leslie M., Timothy D. Hovezak, and Richard H. Wilshusen

2000 Cultural Landscape of Dinétah: The Navajo Occupation of Frances Mesa. In The Frances Mesa Alternative Treatment Project: New Interpretations of the Ancestral Pueblo and Navajo Occupations in the Navajo Reservoir Area, compiled by Richard H. Wilshusen, pp. 159-253. La Plata Archaeological Consultants, Research Paper No. 3. Dolores, Colorado.

Sharp, Kayeleigh, and Melissa Litschi

2014 Maximizing E-Data Collection: A Novel Approach for Data Collection and Transmission Using Tablet Technology. Advances in Archaeological Practice 2(2):104-122.
Shott, Michael J.

1985 Shovel-Test Sampling as a Site Discovery Technique: A Case Study from Michigan. Journal of Field Archaeology 12(4):457-468.

Wells, Joshua J., Andrew A. White, Eric Kansa, Sarah W. Kansa, Stephen J. Yerka, David G. Anderson, Thaddeus Bissett, Kelsey Noack Myers, and R. Carl Demuth

2014 Changing Households and Rising Seas: Two Perspectives on the Potential of Using the Digital Index of North American Archaeology (DINAA) to Link Datasets. Poster presented at the 2014 Annual Meeting of the Midwest Archaeological Conference (MAC). Electronic document, http://www.academia.edu/8615344/Changing Households and Rising Seas Two Perspectives on the Potential of Using the Digital Index of North American Archaeology DINAA to Link Datasets, accessed November 2, 2015.

Wilshusen, Richard $\mathrm{H}$

2015 Surveying the Field: Finding Common Cause in the Three Archaeologies. Presented at American Cultural Resources Association, Broomfield, Colorado. Digital document, (tDAR id: 399663) doi:10.6067/ XCV8G07042, accessed February 9, 2016.

\section{AUTHOR INFORMATION}

Richard H. Wilshusen — PaleoCultural Research Group, Boulder, CO 80304 (rhw1883@gmail.com)

Michael Heilen 1 Statistical Research, Inc., Haymarket, Virginia 20169 (mheilen@sricrm.com)

Wade Catts Commonwealth Heritage Group, West Chester, PA 19380 (wcatts@chg-inc.com)

Karyn de Dufour Nevada State Historic Preservation Office, Carson City, NV 89701 (KdeDufour@shpo.nv.gov)

Bradford Jones Texas Historical Commission, Austin, TX 78701 (Brad. Jones@thc.state.tx.us) 